\title{
On the Frontline or on the Side-line? Homelessness Care and Care Avoiders
}

\begin{abstract}
Homelessness is a social problem which is subject to many definitional issues and problems.

These problems can be discerned on both the conceptual and the practical level (Hopper, 1997). Based on research carried out in Ghent, Belgium, this article deals with ways in which social workers involved in homelessness care construe the problem of 'care avoiders', who seem to be perceived as a separate category within the homeless population. We show that (1) different categories of homelessness are created on an organisational and on an individual level; (2) specific services have been developed for those who do not enter regular facilities and (3) a residual group has been created, which social work does not really know how to deal with.
\end{abstract}

Keywords: social work; homelessness; hard-to-reach clients; outreach; care avoidance 


\section{Introduction}

Many authors point to homelessness as a major and growing social problem worldwide (Horsell, 2006; FEANTSA, 2009). Homelessness is dominantly seen as an important problem of poverty (Anderson, 2004). However, in different periods of time, various conceptions have been used to label the same population of 'homeless' people (Hopper, 1997). 'Vagrancy', in particular, was a term commonly used to typify a largely criminalised population in Western society (Esmonde, 2002). With the decriminalisation of vagrancy and the subsequent welfare approach, vagrancy was redefined as homelessness - a problem of poverty. However, the definition of homelessness is still subject to many disputes (Busch-Geertsema, 2010). Hopper (1997) contends that disputes about the definition of homelessness have their roots not only in conceptual difficulties, but - mainly - in practical utilities. In this article we will put forward that definitions of homelessness are co-construed by choices made through interventions targeting the homeless. We will focus on the category of homeless people perceived as 'unwilling' to engage with services and labelled 'care avoiders'. Those who do not engage in services, but are perceived by social workers as in 'need' of some kind of intervention, are often problematised (Maeseele et al., forthcoming).

Internationally, the greater part of the body of knowledge about this category has been developed in mental health studies and drug studies. Social work seems to be largely absent from these discussions, leaving the debate to academics who focus on the elements of mental illness and drug abuse (or a combination of both: dual diagnoses). The dominant thread in the argument is that the underlying problem of non-engagement is found with the persons themselves and their earlier experiences with social services. Interventions such as casemanagement and assertive outreach are commonly perceived as solutions. 
In this article the central research question is how social work, and more specifically homelessness care, as an actor in social policy making (Evans \& Harris, 2004), deals with what is called 'care avoiders'. We explore the perspectives of social workers working with homeless people in homelessness care in Ghent, Belgium, with a focus on the contribution of the homelessness practice to the realisation of human dignity and social justice proclaimed in the international definition of social work (IFSW, 2000). We demonstrate that 'avoiding care' leads to the creation of a whole new array of organisations with a low threshold and with no specific aim for change. We ask who these 'care avoiders' are, what social services are (or are not) developed and what the underlying argumentation is. We explore what avoiding care means for homelessness care and we emphasise how the behaviour demonstrated by 'care avoiders' could be seen as a challenge rather than as a threat to social work. A proper understanding of social problems and the reactions to them requires a historical perspective (Lorenz, 2007). We start with a short historical outline in which we demonstrate the shifting definitions of the problem of homelessness throughout Belgian history, and the creation of the category of care avoiders.

\section{From Accessibility to Inaccessibility}

The Belgian criminal law of 1867 defined vagrancy as (1) not having a stable residence, (2) not having the necessary means to survive, and (3) lack of employment. A prison sentence was imposed on people who were found to be in this situation. In 1891 a new law was voted in, known as the Law to Curb Vagrancy and Mendicancy. Under the law vagrancy remained a crime but was no longer punished in the traditional sense of the word. A sanction was set by which it was expected that the vagrant would be able to function in society. Depending on the court ruling, vagrants were put in either a Vagabond or a Mendicancy Colony. In a 
Mendicancy Colony, 'professional vagrants' were locked up for a period of between two and seven years. In a Vagabond Colony, 'occasional vagrants' were locked up for a maximum period of one year, against their will.

In the 1960s and 1970s, private small-scale reception centres (where homeless people could stay for a couple of months and where active engagement to change their situation was expected) came into being. These worked with another definition of the problem, 'homelessness', and in the 1980s such organisations started to criticise the penal approach to vagrancy (Neirinckx, 1989). They argued that the face of vagrancy had changed and that new groups were entering the field. Homelessness as a definition became more open and referred to a process of individual, relational and social vulnerability. One of the definitions given to vagrants by those in the homelessness sector was that vagrants were those homeless for whom no social solution was found (Lescrauwaet et al., 1986). This suggests that there was a problem of 'accessibility' in the homeless sector, into which the criminal justice system fitted perfectly in relation to those homeless whom nobody knew how to handle. This was also confirmed in research (Neirinckx, 1989) showing that the homelessness sector counted on the Colonies to take care of difficult clients who could not enter or were excluded from homelessness care.

The formal decriminalisation of vagrancy happened through the Urgency Law for a more Solidary Society in 1993. This Law empowered the municipal Public Centres for Social Welfare (PCSW) to secure the right to social welfare and execute the right to a basic minimum income. The many private small-scale organisations dealing with homelessness were incrementally integrated into private, but subsidised, Centres for General Welfare Work (CGWW). These centres continue to organise most homeless care. They work at a regional level, with their mission the provision of social assistance to persons whose welfare is threatened or diminished because of personal, relational, family or social factors. 


\section{Our Research}

The data presented below are based on semi-structured interviews and analysis of policy documents. The interviews were conducted with 50 social workers and their supervisors working in the broad area of the homelessness sector in the city of Ghent. This means that every organisation working in what is defined as homelessness care was included in the interview. In addition, organisations which were not included in this grouping but were nevertheless emphasised by the interviewees as playing a crucial part in homelessness care were included. An interview was conducted with a social worker and supervisor from every organisation. The interviewees were asked about their ideas of homelessness, the organisation of homelessness care, their own concrete practice and the problems they encounter. The interviews generally took between one hour and one hour and 30 minutes. They were transcribed and analysed using Nvivo8, with which the broader themes in the data, and the tensions in which practices work, could be identified. Additionally, a content analysis was conducted on policy documents from the different organisations which were included in the research. These documents mainly contained reports about the functioning of the organisation and its future policy.

Ghent is the capital of the province of East Flanders. It houses two CGWWs and a municipal PCSW. The city, the PCSW and other local actors have by decree the obligation to collaborate so as to increase the realisation of the social rights enshrined in the Belgian constitution. The city of Ghent is particularly interesting, because the bulk of homelessness care is provided in the cities and Ghent, in contrast to other Flemish cities, seems to attract homeless people from both urban and rural areas in the neighbourhood (Lescrauwaet, 2008). 


\section{The Organisation of Homelessness Care: Creaming}

According to Campbell and McCarthy (2005), the organisation of homelessness care leads to a creaming of those easiest to engage in their goals. In our research, we found that three elements generally contribute to this: (1) the dominant conceptualisation of voluntariness, (2) the profile of homelessness in regular homelessness care (reception centres and supervised independent living) and (3) the creation of an intake centre as a gateway to regular care.

First, the homelessness sector is based on voluntariness in the sense that assistance must be asked for and/or be accepted. The overall approach assumes that clients are aware of their problems, want help and are willing to build a relationship with a social worker. In a previous article we have shown that the notion of voluntariness is often limited to the choice between either entering regular care and accepting the conditions provided, or slipping from social workers' grip and disappearing out of sight (Maeseele et al., forthcoming). To avoid the latter, as we argue below, a whole new array of low-threshold organisations was created.

Second, the research shows that in practice, homeless people entering regular homelessness care generally have to comply to a specific profile (see also Schout et al., 2011). As such homeless are commonly considered those people who are able to comply to the set of criteria in reception centres, where homeless people can generally stay for six months and have to actively engage in change, and supervised independent living, where people are guided in their own housing accommodation: they have no house, no other place to sleep than homelessness care, no (dominant) psychiatric problems and/or drug addiction, no mental or physical disability, show motivation to change, are able to live and function in a group, are able to conform to the internal rules of the centre and do not have a problem with guidance by a variety of social workers. They have to agree to the loss of their income, because they have to pay a daily amount to the reception centre and only receive some pocket money. This also 
means that the homeless person must have an income. In this sense, the homeless have to be active in receiving an income either through waged labour or through activation criteria coupled to social security benefits. This active engagement is also translated in action plans.

Third, in 2008 an intake centre opened in Ghent. An organisation created by both CGGWs, it deals with all the CGGWs' residential homelessness care intake and, as such, regulates access to them. It can be seen as the gateway to regular homelessness care. The logic behind it is to grant access to residential beds only to those in 'real need' and with whom change can be pursued with. In the intake centre the criteria and requirements used by reception centres are explained; they emphasise the active engagement of the client in change, explain the rules of the reception centre household and check whether or not the clients have a mental illness or addiction problems. Interviewees generally agreed that the creation of the intake centre led to a higher access threshold. Before it was opened, there had been the possibility to shop around the different reception centres. A social worker from the intake centre noted that 'a lot of people cannot access regular care and there is no real alternative [to the intake centre]'.

Our analysis showed that regular homelessness care holds the risk of creaming effects in which "the "best" of the homeless population will be "served"' (Bridgman, 2002, p. 58). The developments described above are important contributing factors to the creation of a new category called care avoiders. Those working in reception centres defined their target population as different from this category of homeless people. For example, one social worker from a reception centre emphasised:

In our centre we have a selectively chosen population. [...] While outside this centre it is a different story.

\section{Care Avoidance as Social Problem}


Those who do not and cannot enter care are generally problematised because they are perceived by social workers as in need of some kind of intervention. They are referred to as care avoiders (see Elissen et al., 2011) and can be typified as those who are considered hardto-reach (Cortis, 2011). From the interviews, different elements of the phenomenon could be discerned both on the individual level and on the level of social services.

\section{On an Individual Level: the Relationship with Services}

Care avoiders are defined in practice as 'those people that for diverse reasons avoid seeking assistance: feelings of anxiety or bad experiences with diverse forms of social work in the past can be causes. Some stay for a short period in a night shelter, disappear and are re-discovered later by outreach social work' (AZiS, nd), or as 'people that deserve special attention but from negative experiences in the past or from a lack of problem insight ask no help question, avoid care or decline it' (Stad Gent, 2007). A social worker from the PCSW defined them as follows: Either they don't reach the services or they had so many negative experiences with services that they say 'it doesn't help me to go there, they ask me a lot of questions and I don't want to do everything they ask'. [...] Sometimes they have a psychiatric problem. There are a lot of people on the streets that fall by the wayside and there are some problems with the supply.

The definitions above point to six characteristics: (1) negative experiences with interventions; (2) a lack of problem insight; (3) do not want help; (4) often suffer from a mental illness and/or addiction problem; (5) cannot or do not want to enter the supply of homelessness care; and (6) can be found in low threshold initiatives (see below). These characteristics have been 
confirmed in some previous international research (see for example Crane and Warnes, 2001). Care avoiders have also been typified as 'revolving door clients' who make use of different social services and use the same service several times. Even though some interviewees indicated this, general agreement indicated that there was a limited insight into this phenomenon. The above definitions show that the category of care avoiders seems to be adopted by service providers and practitioners to organise and encode members of particular populations on the basis of their relationships with welfare services (Cortis, 2011; Elissen et al., 2011).

On the level of social services: care paralysis

According to Schout and colleagues (2011), the phenomenon of care avoidance is not only an individual characteristic, but is also linked to care paralysis. This term refers to the inability of services to help those clients with multiple and complex problems. To a certain extent, our results confirm this finding. The interviewees highlighted how clients with serious mental illnesses and/or problems of addiction could not enter regular homelessness care. If they have a dual diagnosis they are often rejected from services for the mentally ill, addiction services and regular homelessness care (see Kvaternik and Grebenc, 2009). Those whose problems only just lacked the sufficient severity for them to enter specialist care often had problems which were evaluated as too grave for them to enter homelessness care. A head social worker at a PCSW said:

There are a lot of people on the streets who fall by the wayside. There are shortcomings of services as well. Some people are mentally too ill for a reception centre but not ill enough for a psychiatric centre. Or their drug addiction is too severe for a psychiatric centre or their psychiatric problems are too severe for drug treatment. 
Those situations are often that complex that people are on the edge of different institutions and in the end cannot end up anywhere.

The interviewees also often emphasised their lack of competence to work with these people, because they are not specifically trained for mental illnesses and addiction problems (see Phelan \& Norris, 2008). Ellis (1998) calls this phenomenon 'dumping', pointing to the explicit avoidance of certain categories within care. Kvaternik and Grebenc (2009) emphasise that social work should not give that much weight to these diagnoses, as they are aimed more toward excluding people than providing assistance to the people involved. Thus, in addition to the individual characteristics describing the behaviour of care avoiders, there are characteristics at the level of social services that contribute to the phenomenon of care avoidance.

An overall limited knowledge of the phenomenon

Knowledge of those avoiding care generally seems to be sparse. During the interviews it was clear that social workers from reception centres often had some kind of idea of those not reaching their services, but admitted that they did not really know who they are. The organisational structure of homelessness care in some way makes them 'blind' for these questions and phenomena because the creation of an intake centre took away the direct contact with the diversity of people and help questions. The low threshold initiatives did not really have a clear understanding of the problem, because they collect as little information as possible. This points to the tension between collecting data and the possibility of losing sight of these people because it could increase the threshold with a certain kind of 'blindness' to the diversity in homelessness. In the end it seems that no one really knows who they are. In 
addition to this limited knowledge, homelessness care does not really know what to do with these people (OCMW Gent, 2006). In fact, a CGWW coordinator explicitly asked: 'What do we have to do with them?'

\section{Motivation and Choice}

One of the characteristics of the perspective generally taken on care avoiders is a general perception that they have a lack of motivation to change (for diverse reasons), and choose not to enter those services aiming at change. We will explore this in depth, because it is quite remarkable in a context in which voluntariness seems to be a key feature of social services. The problematisation of this behaviour often has to do with social workers' perception of the situation. The interviewees had a rather ambivalent stance toward care avoiders. They recognise the problematic character of the situations these people are in and emphasise their need for help and how they often lack insight about the problematic nature of their situation; at the same time, however, they do not see interventions as worthwhile without motivation to change and voluntary acceptance of the services.

Research undertaken with homeless people has already pointed out that the lives of the homeless do not revolve around accessing services, and that they often have other priorities which they may choose over using services (Garrett et al., 2008; Elissen et al., 2011). Additionally, the relationship between care avoiders and professionals seems to be heavily influenced by negative attitudes about professionals and service agencies (Behnia, 2008). A social worker at a reception centre commented:

They arrive here and say 'huh' to you. And then you think: 'wow, what did I do?' But you didn't do anything wrong. But there were already 20 social workers before you saying: 'we are going to change something...', it failed and they have to drag this 
along. As a matter of fact, we as homelessness care pay the bills of what failed during previous years. People blame you and say: 'yes, you're going to try as well, but you are social worker number 34'.

Discussions about the 'voluntariness' of clients 'to choose' (Ferguson, 2007) a life on the streets free from all professional interventions are prevalent. The interviewees were indecisive about whether people really can freely choose a life on the streets. The rationalisation made in practice often points toward characterisation of those not using services as having one or the other kind of disorder or addiction which holds them back from searching and/or accepting interference. Some interviewees also pointed to the avoidance of having an 'official' residence as a tool to avoid creditors.

The emphasis on motivation and choice in regular homelessness care seems to lead to exclusion of those who do not choose to enter such care and do not show the motivation required (Phelan \& Norris, 2008). At the same time, it seems that practices that embrace the dominant conceptualisation of 'voluntariness as free choice' as a criterion of access also have problems with not choosing for or leaving these services. Some clients' resistance to help is not necessarily perceived as a difference in problem definition or as a challenge to these services, but is often perceived as typical for individual clients. There is a risk that perceptions regarding responsibility for not finding the appropriate care could shift to the clients, meaning that they are seen as responsible for their enduring homelessness.

\section{An Organisational and Methodical Answer Found in Low Threshold Initiatives}


Internationally, these homeless people are the target of quite diverse policies, ranging from increasing 'voluntariness', for example through outreach, to interventions using law enforcement (Fitzpatrick \& Jones, 2005). In our case study, we found that some low threshold organisations had been created in order for there to be at least some kind of intervention available: these were day centres and night shelters (CAW Artevelde, 2010). Even though they are open to everyone, it seems that a large proportion of people using them are those seen as care avoiders (CAW Artevelde, 2011b). The day centre offers some leisure time activities (coffee, television), some practical facilities (for example internet access) and some formative activities (such as cooking lessons). There 'is nothing that immediately refers to social services' (CAW Artevelde, 2011b, p. 2). The different kinds of night shelters want to contribute to the amelioration of the circumstances in which the homeless live by realising the possibility to sleep in a humane environment and supporting the survival of this part of the population. It is perceived as an initiative that offers services without the explicit intention of providing solutions for problems (CAW Artevelde, 2011a). After finding that the night shelter was structurally used by a small group of persons (called chronic users) who used almost all their allocated nights (there is a limitation of five nights every two weeks) and almost a third of the capacity of the night shelter (LSB, 2008a), a new organisation was created in 2010 to preserve the function of the night shelter as acute help. It specifically aims at those judged as unable to function in the regular housing market or in the available shelter options (LSB, 2008b). The goal of this night shelter plus is to take away some of the burdens which the chronic homeless encounter in day-to-day life and try to get them back in regular supply, to give chronic users of the night shelter a long-term qualitative alternative, stability and the opportunity to rest (CAW Artevelde, 2011a). Residents have to pay, but in return have certainty about their sleeping facilities. One reception centre social worker described the clients found in the various low threshold initiatives: 
The day centre, I think that they work with people who cannot find help anymore or don't want to... The same with the night shelters... Because it is quite a strange population over there. We don't have these, we have pushovers in comparison to them.

Jones and Pleace (2005) have shown that in the UK 'basic services were almost seen as a kind of 'bait' to encourage users to begin a process by which they could access the services necessary to begin to progress on from daytime homelessness'. A similar development could be discerned in Ghent, where interviewees from day centres and night shelters expressed their hope that humane sleeping and daytime activities would trigger the homeless persons to seek change.

In addition, organisations specifically aimed toward tackling the characteristics associated with care avoidance have been created are perceived as helpful in working with this population: they are targeted at those with a mental illness and those with drug addiction problems. For these people, who generally cannot enter regular homelessness care and can easily be filtered out of the low threshold initiatives as well (because drugs cannot be used and causing nuisance is an exclusion criteria), two specific organisations are available; neither is solely focused on 'homelessness', but homeless people comprise a large part of the population of both. One of the organisations tries to build a network for care avoiders with a psychiatric disorder and dual diagnosis, so that the partners involved engage themselves to find an answer to the avoidance of care. The other organisation provides harm reduction for people with addiction problems.

What we can see here is that the search for an answer to the problem of care avoidance has led to two developments: firstly, new institutions and methods were developed; secondly, when these institutions were perceived as insufficient, this led to the creation of further new institutions. While these low threshold organisations often play an important role in the day- 
to-day routine and survival strategies of the homeless (Zufferey \& Kerr, 2004), at the same time it can be observed that they risk tolerating the problem. As such, they could be seen to follow a specific conception of social justice and social integration largely based on individual choice and individual responsibility. Social workers work on a quite normative perspective of social integration and as such can easily co-opt in exclusionary lines but could also facilitate and promote alternatives.

The low threshold initiatives, and especially the night shelters, in many ways resemble the 19th-century poor houses that provided shelter for those who were displaced, poor and/or mentally or physically ill (Hartman, 1989). Our findings suggest that those who were interned in Vagabond Colonies in Belgium during the second half of the 20th century, namely those who were too difficult for homelessness care (Neirinckx, 1989), are now those labelled as care avoiders and can to a certain extent be traced in these low threshold organisations.

\section{The Creation of Two Care Circuits: Divided Responsibility}

We can observe the development of two care circuits, which are not completely separate, and seem to focus on different definitions and different populations in the broader category of homelessness. The stronger part of the homeless population can more easily find a place in regular homelessness care. A CGGW coordinator stated:

The underlying thought is that every roofless person has in one way or the other a provision of care, and can use it and, depending on the stage they are in, can choose for themself where they want to end up. There are homeless people that absolutely don't want guidance and social workers. Ok, they can go to the day care centre or the night shelter. 
For those labelled as care avoiders, the second circuit was created, offering access to a basic package of homelessness care of initiatives that do not directly strive for change. A social worker from a day centre illustrated this:

From $9 \mathrm{~h}$ in the evening until $9 \mathrm{~h}$ in the morning they have the night shelter. From $9 \mathrm{~h} 30$ to $17 \mathrm{~h}$ they have the day centre and if they have a question they can go to the bridge team.

The Development of 'New' Methods: Outreach

Even though there is a consensus on the problem of care avoidance, the interviews showed quite some ambivalence regarding other perceived 'solutions'. Some interviewees pleaded for more places in homelessness care, others for alternative forms of help. One common solution, however, was found in the development of outreach social work. With this it is believed that care avoiders can be brought back within regular supply. The bridge team, street corner work and PCSW outreach are initiatives that go out and seek homeless people who are perceived as not finding their way into regular services. Also, internationally, outreach is often proclaimed as a solution to bring these people back within the reach of social work or other initiatives (see for example Crane \& Warnes, 2001; Minghella et al., 2002). Outreach is, then, defined as 'any attempt to take a service to people who need it and who would otherwise probably not use the services' (Pierson \& Thomas, 2002, in Andersson, 2011, p. 5). Outreach is often perceived as a way to overcome some of the difficulties that are identified and associated with the voluntariness of social services. A head social worker at a PCSW said:

Now we try to search them ourselves. In the first place we want to build a trusting relationship because in the end searching them does not mean that they will agree with assistance. 
The outreach component thus can be perceived as a connection between both circuits described above. The development of new organisations, methods and techniques shows that homelessness care is largely focused on questions of accessibility and the development of adequate methods to solve social problems, which carries the risk of entangling social work in an introspective debate. Our findings also show the shift from a certain form of guaranteed care to uncertain care with the decriminalisation of vagrancy in Belgium. Where those not choosing or excluded from regular homelessness care before decriminalisation had the guarantee of internment in a Colony, which they used instrumentally - for example, approximately $80 \%$ of the vagrants voluntarily identified themselves to the police (Neirinckx, 1989) - nowadays there is no guaranteed alternative. There seems to be a greater permissiveness toward the problem of homelessness, in which the element of choice seems to be pivotal.

The concept behind outreach is as old as social work and can be seen, for example, in the 'friendly visitors' who visited poor families to improve their morality (Andersson, 2011). The method of outreach social work, however, is ambiguous. On the one hand it seems to be a quite logical evolution of social work to search for those who do not find the supply themselves. Social reality, as we have tried to show, is often more complex. Outreach, first of all, offers no guarantee that people will accept interference and hides the negative experiences which keep some of the homeless away from invoking interventions. It is focused on the connection between supply and demand and is a rather technical method to tune both in this sense that it tries to solve the tension by creating a new method. The policy of outreach practices in some ways conceals questions about accessibility, in which this accessibility is broadened to focus on the more complex connections people have with society and social work practices, with often conflicting problem definitions and associated questions of power and self-determination. 


\section{Discussion}

The problem of care avoiders is co-created and co-construed through the way in which social work practices have developed. On the one hand, it shows the power of homelessness care to create categories of people, to include and exclude groups and to re-confirm diagnoses, and on the other hand it illuminates the tensions homelessness care works in and with (Schuyt, 2004). Those who do not fit the requirements of voluntary compliance to social works' norms and values are often problematised. Hence, care avoiders is a layered label used to typify those who do not want to participate, who cannot participate or who cannot enter regular homelessness care. Literature and practice often tend to rationalise such non-voluntary acceptance of interventions by ascribing and/or emphasising care avoiders' diagnosis of mental illness and/or drug addiction.

It is not our intention to question the usefulness of diagnoses, but we want to point out that non-voluntary acceptance of interventions can be interpreted more broadly than in simple terms of individual deficiency; it can also be seen as a challenge to homeless practices to think about the developed policies and their exclusion mechanisms (Cortis, 2011). According to Kvaternik and Grebenc (2009, p. 518), 'Diagnoses are important for social work only as far as questions about how the person lives with the diagnosis/es, how the diagnosis/es changes their world, or how the medication influences their everyday life'. Social work, then, should be focused on the complexity of the everyday situations people are in, instead of exclusively focusing on the diagnoses these people have received (Kvaternik \& Grebenc, 2009).

If we deem social work to be a democratic space that is open for discussion and deferring opinions (Biesta, 2011), then the problem of care avoiders could also be seen as a challenge, rather then solely a problem of people who are out of order. It challenges social 
work to reflect on who these people are and what their non-voluntary acceptance of interventions means. As such, it offers the possibility of developing a practice which continues to search for a temporary but feasible balance between individual aspirations, mutuality and democratic solidarity (Roose et al., 2010). The category of care avoiders seems to be a category which is not often seen, heard or taken into account (Kvaternik \& Grebenc, 2009). In the perspective of social work as a democratic space, this category becomes visible and taken into account just because of their out-of-order behaviour. Then, commitment of social services, interaction and dialogue in the social work relationship becomes more important than accessibility and choice.

Those who do not rely on regular services offer the possibility of breaking open the discussion on accessibility to encompass broader discussions on the role and position of homelessness care and, even more broadly, of social services in society. The focus then shifts from the choice of (possible) clients toward how policy, organisations and social workers position themselves in relation to both a problem and the debate about the definition of such problems. Reflecting on care avoidance then carries the possibility of transforming social work itself (Clarke, 2004). As such it nuances social work interventions and can make us reflect upon the norms and standards social work stands for and consider the idea that social work may not necessarily be the type of intervention people need in their lives.

\section{References}

Anderson, I. (2004) 'Housing, homelessness and the welfare state in the UK', European Journal of Housing Policy, vol. 4, no. 3, pp. 369-389.

Andersson, B. (2011) 'Finding ways to the hard to reach - considerations on the content and 
concept of outreach work', European Journal of Social Work, DOI:10.1080/13691457.2011.618118

Azis (nd) Doelgroep en doelstelling van Azis, [online] Available at: www.azis.be

Behnia, B. (2008) 'Trust development: a discussion of three approaches and a proposed alternative', British Journal of Social Work, vol. 38, no. 7, pp. 1425-1441.

Belgian Chamber of Representatives (1992) Verslag namens de commissie voor de volksgezondheid en het leefmilieu 9 november 1992, pp. 630/5 -91/92.

Biesta, G. (2011) Learning democracy in school and society, Sense Publishers, Rotterdam.

Bridgman, R. (2002) 'Housing chronically homeless women: inside a "safe" haven', Housing Policy Debate, vol. 13, no. 1, pp. 51-81.

Busch-Geertsema, V. (2010) 'Defining and Measuring Homelessness', in Homelessness research in Europe, (eds.) E. O'Sullivan, V. Busch-Geertsema, D. Quilgars \& N. Pleace, Feantsa, Brussels.

Campbell, G.J. \& McCarthy, E. (2005) 'Conveying mission through outcome measurement: services to the homeless in New York City', Policy Studies Journal, vol. 28, no. 2, pp. 338-352.

CAW Artevelde (2008) Jaaroverzicht 2007, CAW Artevelde, Gent.

CAW Artevelde (2010) Beleidsplan 2011-2015, CAW Artevelde, Gent.

CAW Artevelde (2011a) Jaarverslag nachtopvang 2010, CAW Artevelde, Gent.

CAW Artevelde (2011b) Jaarverslag SOC 2010, CAW Artevelde, Gent.

Clarke, J. (2004) 'Access for all? The promise and problems of universalism', Social Work \& Society, vol. 2, no. 2, pp. 216-224.

Cortis, N. (2011) 'Overlooked and under-served? Promoting service use and engagement among ‘hard-to-reach' populations', International Journal of Social Welfare, Advance access: DOI: 10.1111/j.1468-2397.2011.00825.x 
Crane, M. \& Warnes, A.M. (2001) 'The responsibility to care for single homeless people', Health and Social Care in the Community, vol. 9, no. 6, pp. 436-444.

Ellis, R.P. (1998) 'Creaming, skimping and dumping: provider competition on the intensive and extensive margins', Journal of Health Economics, vol. 17, no. 5, 537-555.

Elissen, A.M.J., Van Raak, A.J.A., Derckx, E.W.C.C. \& Vrijhoef, H.J.M. (2011) 'Improving homeless persons' utilisation of primary care: lessons to be learned from an outreach programme in The Netherlands', International Journal of Social Welfare, Advance access: DOI: 10.1111/j.1468-2397.2011.00840.x

Esmonde, J. (2002) 'Criminalizing Poverty: the Criminal Law Power and the Safe Streets Act', Journal of Law and Social Policy, vol. 17, pp. 63-86.

Evans, A. \& Harris, J. (2004) 'Street-level bureaucracy, social work and the (exaggerated) death of discretion', British Journal of Social Work, vol. 34, no. 6, pp. 871-895.

FEANTSA (2009) Ending homelessness: a handbook for policy makers, Feantsa, Brussels.

Ferguson, I. (2007) 'Increasing user choice or privatizing risk? The anitomies of personalization', British Journal of Social Work, vol. 37, no. 3, pp. 387-403.

Fitzpatrick, S. \& Jones, A. (2005) 'Pursuing social justice or social cohesion?: Coercion in street homelessness policies in England', Journal of Social Policy, vol. 34, no. 3, pp. 389-406.

Garrett, S.B., Higa, D.H., Phares, M.M., Peterson, P.L. Wells, E.A. \& Baer, J.S. (2008) 'Homeless youths' perceptions of services and transitions to stable housing', Evaluation and Program Planning, vol. 31, no. 4, pp. 436-444.

Hopper, K. (1997) 'Homelessness old and new: the matter of definition', Housing Policy Debate, vol. 2, no. 3, pp. 9-67.

Horsell, C. (2006) 'Homelessness and social exclusion: a Foucauldian perspective for social Workers', Australian Social Work, vol. 59, no. 2, pp. 213-225. 
IFSW (2000) International definition of social work, Available at: http://ifsw.org

Jones, A. \& Pleace, N. (2005) Daytime homelessness, University of York: Centre for Housing Policy, York.

Kvaternik, I. \& Grebenc, V. (2009) 'The role of social work in the field of mental health: dual diagnosis as a challenge for social workers', European Journal of Social Work, vol. 12 , no. 4 , pp. 509-524.

Lescrauwaet, D. (2008) Cliëntstromen in de residentiële opvang. Steunpunt Algemeen Welzijnswerk, Berchem.

Lescrauwaet, D, Neyrinckx, P. \& Van Menxel, G. (1986) 'Het aktie-onderzoekscentrum thuisloosheid over landloperij: armoede achter slot en grendel', Panopticon, vol. 7, no. 2, pp. 167-169.

LSB (2008a) Verslag rondetafelgesprek dak-en thuisloosheid, [online] Available at: http://lokaalsociaalbeleidgent.be

LSB (2008b) Nachtopvang+, [online] Available at: http://lokaalsociaalbeleidgent.be

Lorenz, W. (2007) 'Practising history: memory and contemporary professional practice', International Social Work, vol. 50, no. 5, pp. 597-612.

Maeseele, T., Roose, R. \& Bouverne-De Bie M. (2012) 'Voluntariness as legitimation for social work interventions', Manuscript submitted for publication.

Minghella, E., Gauntlett, N. \& Ford, R. (2002) ‘Assertive outreach: does it reach expectations?', Journal of Mental Health, vol. 11, no. 1, pp. 27-42.

Mouffe, C. (2005) On the political, Routledge, London / New York.

Neirinckx, P.M. (1989) Armoede achter slot en grendel? Op weg naar een decriminalisering of depenalisering van de landloperij, Koning Boudewijnstichting/vereniging der Vlaamse Onthaaltehuizen/Associations des Maisons D’acceuil, Brussel. OCMW Gent (2006) Beleidsnota OCMW 2007-2012, OCMW Gent, Gent.

Phelan, E. \& Norris, M. (2008) 'Neo-coporatist governance of homeless services in Dublin 
Reconceptualization, incorporation and exlusion', Critical Social Policy, vol. 28, no. 1, pp. 51-73.

Roose, R., Coussée, F. \& Bradt, L. (2010) 'Going beyond the bounds of possibility: questioning the delimitation of the social in social work', Social Work \& Society, vol. 8, no. 1, pp. 1-5.

Schout, G., de Jong, G. \& Zeelen, J. (2011) 'Beyond care avoidance and care paralysis: theorizing public mental health care', Sociology, vol. 45, no. 4, pp. 665-681.

Schuyt, T.N.M. (2004) 'The magnetism of power in helping relations. Professional attitude and asymmetry', Social Work \& Society, vol. 2, no. 1, pp. 39-53.

Stad Gent (2007) 'Beleidsnota straathoekwerk 2008-2013’, Stad Gent, Gent.

Stanhope, V., Henwood, B.F. \& Padgett, D.K. (2009) 'Understanding service disengagement from the perspective of case managers', Psychiatric Services, vol. 60, no. 4, pp. 459464.

Zufferey, C. \& Kerr, L. (2004) 'Identity and everyday experiences of homelessness: some implications for social work', Australian Social Work, vol. 57, no. 4, pp. 343-353. 